\title{
TRADUÇÃO
}




\section{Gautier de Coincy: um cantor da Virgem}

Ângela Vaz Leão

UFMG e PUC Minas

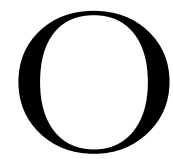
culto à Virgem Maria, no Ocidente Europeu, até por volta do séc. XI exprimiu-se em preces e hinos, que eram escritos e cantados em latim. A partir daí é que começam a aparecer coleçôes de poemas marianos nas línguas vernaculares nascentes. Dessas coleçōes, chegaram até nós, entre outras, as dos seguintes poetas:

- Gautier de Coincy: cerca de 60 poemas compostos em francês antigo, possivelmente com traços do dialeto picardo;

- Gonzalo de Berceo: 25 poemas, em castelhano arcaico;

- D. Afonso X, o Sábio: 420 poemas em galego-português do século XIII.

Gautier de Coincy talvez seja, entre nós, o menos conhecido dos três poetas. É dele que vamos falar aqui, começando por uma breve notícia de sua obra, para depois apresentar um dos seus poemas no original, acompanhado de nossa tradução para o português contemporâneo. O poema selecionado foi o conhecido "milagre do judeuzinho", intitulado Du filz au juif qui à Borges fu délivré du brasier par le miracle Nostre Dame (Do filho do judeu que foi livrado das chamas, em Bourges, por milagre de Nossa Senhora).

Gautier manifesta, no poema, sua simpatia e carinho pelo menino judeu, mas, ao contrário, descarrega sobre o pai toda a antipatia, se não ódio, que nutre pelos judeus.

$\mathrm{Na}$ tradução, procuramos manter a possível fidelidade ao conteúdo, além de relativa aproximação de algumas das técnicas versificatórias de Gautier. Sirvam de exemplo as rimas emparelhadas duas a duas, do início ao fim do poema,assim como o artifício poético utilizado na parte final da composição, caracterizado pela repetição de uma mesma palavra em suas 
formas derivadas, isto é, dentro da mesma família lexical. Salvo melhor interpretação, esse é um procedimento comparável ao mordobre da poesia galego-portuguesa e constitui, na poesia de Gautier de Coincy, uma presença freqüente, quase um cacoete estilístico, no final dos poemas.

Para situar o leitor em relação à obra dessa grande poeta, damos abaixo uma síntese dos marcos cronológicos mais importantes da sua biografia: 1177 ou 1178 - nascimento de Gautier, em Coincy (nordeste da França); 1193 - entrada no monastério beneditino de Saint Médard, em Soissons; De 1193 a 1214 - permanência no mosteiro beneditino de St. Médard; 1214 - exercício do priorado de Vic-sur-Aisne;

1233 - nomeação para o posto de "Grand Prieur" da igreja de Saint Médard, Soissons;

1233-1236 - ocupação do mesmo posto, importante na hierarquia da Igreja;

1236 - morte de Gautier de Coincy.

A parte principal da obra de Gautier de Coincy constitui-se, como já dissemos, de uma coleção de cerca de 60 narrativas, em versos, de milagres da Virgem Maria, intitulada Miracles de Nostre Dame. O poeta exprime aí sua fervente devoção a Santa Maria, que ele faz intervir na vida dos homens, como mediadora entre estes e a divindade.

Entre os cantores da Virgem que conhecemos em línguas vernáculas, cronologicamente falando Gautier de Coincy foi o primeiro. Dos poemas que nos deixou transcrevemos apenas um, para mostrar a excelência de sua arte e o virtuosismo de seus procedimentos. Traduzindo-o para o português moderno, talvez não tenhamos conseguido evidenciar essas qualidades, pois nossa tradução pode não ter sido o exercício de recriação poética que toda tradução tem a obrigação de ser. Insistimos, porém, em algumas das características do nosso trabalho:

a) manutenção do número de versos do original, num total de 142;

b) reprodução do esquema rimático, constituído de rimas emparelhadas duas a duas, todas elas consonânticas, com apenas quatro exceçōes, onde, 
não conseguindo a rima consonântica adequada, lançamos mão de rimas toantes ou assonantadas;

c) observância apenas aproximada (ou não observância) da métrica, que, no original francês, oscila entre versos setissílabos e octossílabos, graves ou agudos;

d) tentativa de reproduzir, na tradução portuguesa, um procedimento do original que aparece nos últimos 12 versos, a partir do verso no 131 , onde começa o último período do poema. Trata-se, conforme já foi dito, da reiteração de elementos lexicais, de uma mesma família, no caso presente portadores do sema $d u r-$, radical que veicula, com insistência, três idéias aí associadas:

- a de dureza, no sentido moral, qualidade negativa atribuída aos judeus (ex: dur, dure, durement);

- a de persistência ou duração dessa característica através dos tempos (ex. verbo durer);

- e a de não tolerância de Nossa Senhora e do próprio Poeta em relação a essa dureza permanente dos judeus (ex. verbo endurer, em construções negativas, significando "não tolerar, não suportar").

As informações acima e a tradução do poema são de nossa inteira responsabilidade.

A bibliografia limita-se a às fontes textuais e a poucas obras portadoras de alguns dados pertinentes ao assunto:

1 - COINCY, Gautier de. Miracles de Nostre Dame, Ed. E. F. Konig, 4 vol, Gèneve: Libraire Droz, 1955-1970. (Só tivemos acesso ao 4 o vol).

2 - COINCY, Gautier de. Miracles de Nostre Dame, Ed. Abbé Poquet. Paris, 1857. Réimpression: Genève, 1972. (Essa foi a edição que utilizamos)

3 - Dicionário HOUAISS da Lingua Portuguesa. Rio de Janeiro: Objetiva, 2001.

4 - Le Micro-Robert: langue française plus noms propres, chronologie, cartes. Redaction dirigée par Aloin Rey. Paris: Dictionaires Le Robert, 1988. 
5 - MIRI, Rubin. Mother of God. A history of the Virgin Mary. New Haven and London: Yale University Press, 2009, p. 228.

6 - KATLEN, Kulp-Hill. Songs of Holy Mary of Alfonso X, the Wise. Arizona, Tempe, 2000, p. 6-7.

7 - Littérature Française. Publiée sous la direction de Joseph Bédier et Paul Hazard. Paris Larousse, 1948 - Tome premier, p.74-76.

8 - SILVA, Joaquim Carvalho da. Dicionário da Lingua Portuguesa Medieval. Londrina: Eduel, 2007.

Vamos agora ao poema e sua tradução:

\section{DU FILZ AU JUIF QUI A BORGES FU DELIVRE DU BRASIER PAR LE MIRACLE NOSTRE DAME.}

Gautier de Coincy

1 À Bourges ce truis lisant

D'un juif verriers, mesdisant,

Fist Nostre Dame tiex merveilies

Pieça noistes ses pareilles.

Un juif out en un juitel

Mieus entendant et moult plus bel

De touz les autres juitiaus.

Por ce quil liert plaisans et biaus,

Tuit li clerçon de la cité

10 Le tenoient en grant chierté;

Souvent aloit à leur escole.

La char qu'il avoit tendre et mole

Souvent son père li batoit

Por ce que à l'escole aloit.

Tant y ala et tant y vint,

Ainsi com Dieu plout qu' il avint

Qu'a. Pasques vit communier

Pluseurs clerçons à un moustier.

Entr' eus se mist por faire autel.

20 Un ymage out desus l'autel

Qui moult estoit de bêle taille;

Desus son chief une touaille,

\section{DO FILHO DO JUDEU QUE FOI SALVO DO FOGO, EM BOURGES, POR UM MILAGRE DE NOSSA SENHORA.}

Ângela Vaz Leão

Em Bourges, segundo o que achei escrito, com um judeu vitralista, maldito, fez Nossa Senhora maravilha tal que há muito não ouvistes outra igual.

Um menino judeu, numa judiaria, mais belo era e melhor ler sabia do que qualquer outro judeuzinho. Pelo muito que era belo e bonzinho todos os coroinhas da cidade lhe dedicavam grande amizade. Com frequência ia ele à escola cristá. Sua carne, que tenra tinha e louçã, muitas vezes seu pai a torturava, porquanto essa escola ele frequentava. Tanto lá foi e tanto de lá voltou, que aconteceu, segundo Deus aprovou, que ele visse, pela Páscoa, comungar os coroinhas, do mosteiro no altar. Entre eles, junto ao altar, já se metia. Uma imagem nesse altar resplandecia que em todo o porte era só encanto; sobre a cabeça ela trazia um manto. 
Un enfançon en son devant. $\mathrm{Li}$ juitiaus quant vint devant La regarda, par grant entente; Quar moult li sembla bèle et gente; Ses cuers li dit bien et révèle, Ainc mes ne vit chose tant bêle. Avis li est en son courage

30 Qu'en lieu du prestre vint l'ymage, Desus l'autel prise à l'oublée Que le prestre avoit sacrée. Si doucement le communie Que li cuers touz l'en rasazie. Chiés son père s'en repaira, Toute sa face se resclaira

De la grant joie qu'il avoit. Quant son père si bel le voit, En contre queurt et si l'embrace.

40 «Bouche si bêle, front et face

" Dont vient, mon filz, » fait il, «si biaus? »

"Biau père, » dist le juitiaus, Com enfes qui ne soit nier, "Je vieng de moi communier, "Avee les clerçons de l'escole." Mais ains qu'out dite la parole, » Contre terre l'a si rué, Par un.petit ne l'a tué. Mautalentis et espris d'ire,

50 Au juitel commence à dire: "Tu es cheus en maus liens, »En despit de toux crestiens, »Et en viltance de leur loi, » " Ferai granz merveilles de toi. » De maltalent et d'ire espris, Par les cheveus l'enfant a pris, Tout débatant le trait grant erre Au fournel où faisoit son voirre. Si l'a geté en la fournaise

60 Qui toute estoit plaine de breze; Et por l'enfant plus espenre, Seches buches queurt li chiens penre. e à sua frente, no colo, um menininho. Ao chegar diante dela, o judeuzinho contemplou-a com grande encantamento, pois, nela viu beleza e talento.

Seu coração bem lhe diz e revela: nunca jamais vira coisa tão bela. Desejo tal lhe veio de comungar, que a imagem se pôs do padre no lugar, pegando a hóstia sobre a ara sagrada, hóstia pelo padre já consagrada. Tão docemente lhe dá a comunhão, que lhe enche de alegria o coração. Para a casa de seu pai ele voltou, e sua face toda se iluminou pelo grande prazer que então sentia. Seu pai, ao vê-lo em tão grande alegria, corre até ele para que logo o abrace. "Que bela boca, e bela fronte e face De onde vem, meu filho, tanta beleza?" "Caro pai", diz o filho com presteza, como criança que não sabe enganar, "a comunhão acabo de tomar com os coroinhas, colegas meus." Mas tão logo ele assim respondeu, jogou-o ao chão o pai e o surrou tanto, que por pouco não o matou. Cheio de grande rancor e desprazer, começa o pai ao judeuzinho a dizer: "Caíste em mau lugar e companhia, embora cristãos sejam todavia. P'ra desprezo de sua lei mostrar, farei contigo coisa de espantar." Tomado de grande ira e mau conselho, agarra o menino pelo cabelo. Este se debatia, mas o pai o arrastava, até o forno onde os vidros fabricava. Aí o jogou, na acesa fornalha, toda cheia de brasa e de borralho. E para mais o menino torturar toras secas vai o cão apanhar. 
S'a la fournaise tost emplie.

La mère aqueurt et brait et crie;

S'afubleure à terre rue;

Paumes batant, saut en la rue;

Ses cheveus ront et detirant.

"Hareu! hareu ! à cest tirant;

"Quar acourez, » fait elle, « tost »

70 En petit d'eure y out tel ost,

De genz y out plus de x mile.

Assemblée est toute ia ville.

Grant noise mainntient et grant bruit.

Au grant brasier sont sailli toit.

Le feu traient de la fornèse;

L'enfant treuvent qui sus ia brèse

S'iert entenduz par tel delit

Com s'il geust en un biau lit.

Ainc en chevel n'en vesteure

80 N'eut arsion ne bruleure.

Graciez en fust Jhésucriz

A haute voiz et à haut criz

De trestouz ceux qui l'enfant virent.

L'enragié chien mouit tost saisirent.

Quant batu l'orent et beté,

En la fornaise l'ont geté.

Le feu si est moult tost aers.

Quant greilliez fu touz et ars,

Entour l'enfant se rassemblèrent.

90 Moult doucement li demandèrent

Comment estoit que touz ne fu

Ars et bruis en ce grant fu?

Tuit s'en merveillent foi et sage.

«Par foi, » fait il, « la bèle ymage

»Qui hui matin me sorriet

"Quant ele m'a communiet,

"Avec moi vint en la fournaise;

" Lors m'endormi si fui aaise,

»Et si me semble bien sanz faille

100 »Qu'el me couvri de sa touaille

"Qu'elle out sus l'autel afublée;

»Puis ne senti feu ne fumée.
Com elas a fornalha é uma só chama. A mãe aos gritos logo acorre e clama; co'a cabeça no chão se precipita, e depois já na rua os braços agita, cabelos puxa e começa a arrancar: "Socorro! Socorro!" põe-se ela a gritar. "Corram aqui!" e os cabelos arrancava. Num instante tanta gente se juntava que mais de dez mil pessoas se contou. Enfim toda a cidade se apinhou.

Em grande tumulto, em corrida ligeira, dirigem-se todos à grande fogueira. Tirando tições, apagam a chama, e vêem o menino como em boa cama: deitado está nas brasas, com deleite, como se estendido fora em belo leito. Nada no cabelo ou na vestidura tinha de ferimento ou queimadura. Foi por isso Jesus Cristo louvado, em altas vozes, como em um só brado.

Os que antes viram o judeuzinho agarraram sem tardar o cão mesquinho. Depois que o maltrataram e surraram, bem no meio da fornalha o jogaram. O fogo nele pegou por todo lado, tão forte que o deixou logo tostado. Em volta do menino se ajuntaram e bem docemente lhe perguntaram como podia ser, por arte ou jogo, não se ter ele queimado no grão fogo, Maravilham-se todos, o são e o demente. "Por Deus!", diz ele. "Preparai vossa mente! A bela imagem que cedo me sorriu, quando então comunhão me repartiu, no fogo acesso comigo veio ter.

Tão bem me senti até adormecer. E bem me parece — deixai de espanto! que ela me envolveu todo com seu manto que tinha na cabeça sobre o altar; depois não senti fumaça nem queimar. 
" Ainz moi tant dormi sus la brèse,

"Qu'encore sui je plus à èse. »

De pitié tuit et toutes pleurent,

Et s'en mercient et aeurent

A jointes mains la bèle Dame

Qui du brasier et de la flame

Par sa douceur l'a délivré.

110 A un provoire 1'ont livré

Qui le bautize à moult grant joie,

La Mère après lui se bautoie

Ou non de sainte Trinité.

Pluseurs juis par la cité

Por le miracle qu'apert virent,

A nostre loi se convertirent,

Dieu servirent toute leur vie,

Et Madame sainte Marie

Qui cest miracle daigna faire

120 Por eus à creance atraire.

Bien leur moustra qu'aveugle estoient

Tuit li juif qui ne croaient

Qu'ele estoit la Virge flourie

Dont Diex paria par Isaie.

Bien leur moustra la damoisèle

Qu'ele iert ia Virge pucèle

Où char et sanc prist Jhésucrist.

Mais devant que viengne antecrist,

Ne crerront il $^{1}$ en prophecie

130 N'en riens nule qu'en leur en die.

En leur erreur ont trop duré ${ }^{2}$
E assim, sobre as brasas tanto dormi, que em bem-estar ainda me sinto aqui."

De piedade choram todas as pessoas e muitas graças dão, cantando loas, de mãos postas, àquela bela Dama que do braseiro mortal e da chama o livrou, por misericórdia infinita. Entregaram-no a um padre eremita que alegremente o batismo lhe deu. A mãe, depois dele, o batismo recebeu, em nome da Santíssima Trindade. E vários judeus daquela cidade, pelo milagre que claramente viram, para a nossa Lei logo se transferiram, e a Deus daí serviram sempre à porfia, como a Nossa Senhora Santa Maria, que esse grande milagre fazer quis, para atraí-los à Lei vera e feliz.

Bem lhes demonstrou que cegos estavam todos os judeus que não acreditavam que fosse ela aquela Virgem em flor de quem por Isaias fala o Senhor. Bem lhes mostrou a jovem bela que ela era a Virgem donzela, de quem carne e sangue tomou Jesus Cristo. Mas antes que à Terra venha o Anticristo, judeus ${ }^{1}$ em profecias não crerão nem em nada que sobre isso lhes dirão. No seu erro por demais eles $\underline{\text { duraram. }} .^{2}$

${ }^{1}$ Esse il, terceira pessoa do plural, no francês arcaico, refere-se aos judeus, objeto do forte anti-semitismo de Gautier de Coincy, do qual ele só exclui os judeus que se convertessem à Lei de Cristo.

${ }^{2}$ A partir do verso 131, esse antijudaismo se exprime por um artifício poético que, típico do estilo de Gautier, aparece nos finais de seus poemas. O procedimento consiste no emprego reiterado de palavras cognatas, no caso presente palavras em que aparece o radical dur-, num total de 16 itens que grifamos, em apenas 12 linhas. 
Si durement sunt a duré,

Que plus sont dure que pierre dure.

Certes hauz hons qui les endure ${ }^{3}$

Ne doit mie lonc temps durer,

Ne doint Nostre Dame endurer

Ne ses douz filz jà ne l'endurt;

Qui les endurt qui jà durt

Trop y a dur endurement

140 Vers eus sui durs si durement

S'estoie roys pour toute roie

Un seul durer je n'en lairoie.
Tão duramente nesse erro perduraram que mais duros são do que pedra dura. Certamente homem bom que os atura, ${ }^{3}$ não pode por muito tempo perdurar. Nossa Senhora não os deve aturar, nem seu doce Filho tão pouco os atura. Quem os atura, se isso ainda perdura, é que muito dura tem a dura mente. Com eles eu sou duro, tão duramente, que, se rei eu fosse, como única via, nem um só deles durar eu deixaria.

${ }^{3}$ A tradução de endurer por aturar quebra, no português, a reiteração do radical $d u r$ - Não encontramos outra solução, que, do ponto de vista semântico, nos parecesse mais satisfatória. 